\title{
O meio de produção como forma e linguagem gráfica: a experiência do fazer como potência no processo ensino-aprendizagem em design
}

Leandro Ferreira Gatinho;

Julie de Araujo Pires

resumo:

Este trabalho é parte de uma pesquisa de mestrado em design, que tem como objetivo geral refletir acerca do exercício de criação e das interações resultantes do processo ensino-aprendizagem no design gráfico, envolvendo diversas técnicas e materiais de produção gráfica em ofsete. Quando ações contidas no processo de produção adquirem outras perspectivas, que não apenas de mera execução, proporcionam olhares diversos. Defendemos que essa atitude pode ser estimulada no estudante de design com intuito de extrair de seus materiais, através da manipulação da matéria, possibilidades geradoras para novas formas. Para isso, ele precisa dominar o processo, por meio da experiência, alcançando não apenas a materialização do seu projeto gráfico, mas tornando o possível real, ao potencializar seu processo criativo do ponto de vista técnico, artístico e projetual, gerando inclusive possibilidades poéticas. Para tal, contribuíram os escritos de Richard Sennett, Gaston Bachelard, Rafael Cardoso, Jorge Larrosa, entre outros.

\section{palavras-chave:}

produção gráfica; artesania; design visual; ensino-aprendizagem 


\section{Introdução}

A multiplicidade de informações e possibilidades existentes nos projetos gráficos no mundo atual, cada vez mais tecnológico, impulsionam sugestivos resultados na mídia impressa e nos diversos meios de informação, gerando assim uma cacofonia e a necessidade de procurar outras formas de expressão, seja pela sensação ou pela busca por distintas formas de leitura, muitas vezes inusitadas, que podem se tornar um caminho interessante para valorizar o produto gráfico contemporâneo.

Ocorre hoje, tanto no design quanto na vida e noutros campos de saber, o pensamento de que quanto mais o ser humano se aproxima de facilitadores tecnológicos em sua prática cotidiana, mais ele tenderia a buscar se expressar por meio da arte, como um impulso básico e permanente necessário, para uma fuga libertária do uso mecanicista, racional e fragmentado da tecnologia. Há, portanto, uma carência de ser surpreendido pelo inusitado, deixar que o projeto gráfico lhe guie por sentidos inversos, diferentes, questionáveis. O que nos faz refletir que, ao retomar nossas práticas por esses estímulos, podemos ver surgir uma forma de valorização da técnica como meio e processo para outras visualidades.

Sob nossa perspectiva, essa busca se promove quando há um olhar próprio do designer para a produção, no qual o estudante de design gráfico, através do domínio de conhecimentos entre diferentes técnicas de se produzir, seja ela tradicional, contemporânea, artesanal ou industrial - como por exemplo na utilização de materiais e processos da pós-impressão - poder experimentar as possibilidades de intervenções criativas desses materiais, quando materiais que são inicialmente destinados para uma função básica são deslocados para outras funções possíveis, em um acontecimento tal qual, como nos descreve Rafael Cardoso, "quando é suspensa a finalidade das coisas".(CARDOSO,2011:123)

\section{A importância da artesania no processo de produção}

Neste sentido, a relação entre a projeção e a execução pode ser entendida na origem da palavra design, vinda do latim "designare". Segundo Cardoso, este verbo contém tanto a definição de designar quanto de desenhar. Ele aponta que, em sua etimologia, o termo já carrega uma duplicação ativa entre o "abstrato (projetar/conceber/atribuir) e o concreto (registrar/configurar/formar)". (CARDOSO, 2008: 20,21). Cardoso ainda sustenta que a relação entre projetar e executar, muito proeminente enquanto qualidade dos antigos artesãos fora distanciada com a revolução industrial, e estima que tais características estejam sendo revistas na intenção de recuperar esta "manualidade" no fazer. De acordo com a filosofia de Platão, na etimologia de "fazer" está contida o vocábulo poiein, do qual se originou o conceito de "habilidade". (SENNETT, 2008:34) Essa relação da habilidade do fazer entre o agente e o artefato é um movimento humano no qual está condicionado à feitura do mesmo. Logo, é necessário que o designer esteja atento não apenas ao que será feito, mas ao modo como será feito.

Neste sentido, o sociólogo Richard Sennett, autor do livro O Artifice, descreve que a habilidade artesanal estaria relacionada a um fazer mais amplo, ligado ao impulso ou desejo do trabalho bem feito. Ele cita a figura do artífice, como aquele que se destina a fazer ou materializar um objeto focalizando a relação entre o corpo e mente. Esta competência humana de engajamento lida diretamente com uma habilidade artesanal e estabelece uma condição que é exercida durante o momento presente levando-nos a um resultado pelo valor de Artesania. ${ }^{1}$

Por esse valor citado, complementa-se com Cardoso (2009) quando este entende ser "um grau alto de atenção e de cuidado na execução, senso peculiar de orgulho no trabalho, do prazer em fazer benfeito". Em relação específica ao designer, o autor complementa que "essa postura costuma estar presente nas soluções dos melhores projetistas". (CARDOSO, 2008: 247) Em seu pensamento, o autor reforça que esta postura infelizmente foi se diluindo ao longo do século XX por ideais que ainda

\footnotetext{
${ }^{1}$ A palavra "artesania" é um neologismo, com origem da língua espanhola, que adotaremos na investigação da pesquisa como uma condição específica que é estabelecida pelo estilo particular do artesão na concepção de um objeto; O termo é utilizado também segundo (Cardoso, 2013) pelo ceramista Gilberto Paim na tentativa de tradução da palavra inglesa craftsmanship. Assim, palavras como, zelo, dedicação, e satisfação de um trabalho bem executado são qualidades que fazem diferença no ato projetual.
} 
permanecem convictos na separação entre o design e a arte ou o design e o artesanato. Ele explica que em épocas antes da industrialização este mesmo valor era muito presente, resgatando-a antiga relação entre mestre e aprendiz. $\mathrm{O}$ aprendizado nos ofícios e profissões era construído durante um longo tempo. O aluno ou aprendiz para se tornar mestre, deveria chegar primeiro ao nível de artífice - aquele que já possui um ofício -, para depois alcançar o nível de mestre - aquele que ensina e orienta.

Dessa forma, estima-se que esse valor cultivado nos remete a momentos históricos importantes para o design, relatados com o intuito de se evidenciar a figura do ser humano que faz e tenta estabelecer uma relação entre pensar e fazer na configuração de objetos. Esses momentos préconfiguram um saber coletivo desenvolvido por ofícios que tinham como objetivo a produção de artefatos conjugada intrinsecamente com a habilidade artística do profissional. Assim, é importante destacar as associações de profissionais (sapateiros, ferreiros, alfaiates, marceneiros, carpinteiros, artesãos, artistas) no período da Idade Média, chamadas de Guildas Medievais. Nestes núcleos os ensinamentos eram passados diretamente na prática de interação entre mestres e aprendizes.

Naqueles ofícios, as relações entre projetar e executar eram muito próximas. Havia a necessidade de um exímio conhecimento entre a técnica e os materiais. Entretanto, essa capacitação era regida de forma coletiva. A oficina era, em um mesmo ambiente, o espaço de habitação, formação e trabalho, todos comandados pelo Mestre. Em comparação à atividade do designer, ressaltamos que, também nela, teoria e prática fazem parte do mesmo projetar e devem estar em harmonia contínua. De acordo com a pesquisadora Regina Barbosa sobre o papel do artesão na obra como um todo:

A obra de arte total se constrói, ou, de fato, é construída, num processo então, de interdisciplinaridade. O projeto é do grupo, não apenas do artista, que detém o conhecimento estético, mas também do artesão, que complementa o projeto com o saber dos processos de construção do objeto. A trabalhar em conjunto, amplia-se os horizontes de ambos, artista e artesão, e é aberto o espaço necessário para explorar novos materiais, criar novas soluções e buscar novas alternativas formais, a fim de inventar um novo mundo. (De MASI apud BARBOSA apud STOLASKI, 2012:117).

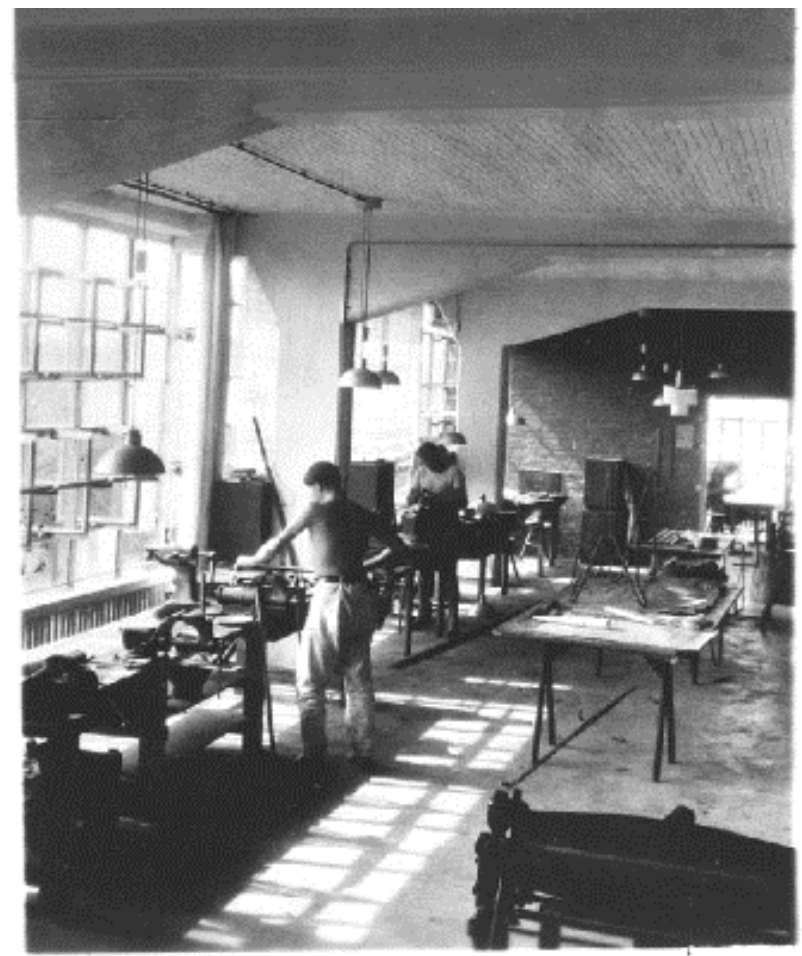

Figura 1 - Atelier Bauhaus, oficina de metal, Dessau, 1927.

Fonte: Livro Bauhaus - Thames \& Hudson world of art, 2010, p.18. 
O sentido do design como uma proposta de aprendizado que inclui a relação entre arte e técnica, característica de atuação da idade média, foi resgatada somente alguns séculos depois, pela Bauhaus, em 1919. Implementada pelo arquiteto alemão, e seu primeiro diretor, Walter Gropius, a escola tinha como propósito justamente esta integração, dispondo de uma estrutura que possibilitasse capacitar profissionais para conhecer todo o processo de produção. Além de estimular a expressão criativa contínua, não apenas inspiração artística, a escola possuía um programa com metodologia pertinente, conjugada por uma racionalização permanente que estivesse perfeitamente em acordo com o planejamento da maquinaria fabril, obtido mediante o processo industrial de produção.

Na primeira fase do curso da Bauhaus, a configuração no aprendizado de ofício submetia cada estudante a escolha de uma oficina no período de formação (figura 1). Nessas oficinas, todos estudavam ao mesmo tempo com dois mestres, um de artesanato e outro de arte/design. O diretor afirmava que a formação artesanal era um meio de educação insubstituível que justificaria seu fim. E Gropius complementa sua afirmação dizendo que "a meta dessa formação era produzir designers, que por seu conhecimento exato do material e dos processos de trabalho estivessem em condições de influir na produção industrial de nosso tempo". (GROPIUS, 1965:40)

$\mathrm{Na}$ visão geral desta primeira fase, a escola tinha como desafio transmitir um saber que não era apenas informativo, mas objetivava instruir o aluno na compreensão geral pela razão e sentido do ofício, permitindo a construção de um entendimento natural da vida como um todo. Seu curso preparatório tinha como destaque a possibilidade de cursar aquilo que Gropius dizia ser uma fase de "experiência primitiva" com materiais e instrumentos variados para assim determinar com mais segurança a escolha de seu ofício natural. Em tal fase, tanto o lado artesão como o viés artístico do estudante tinha que ser amplo o suficiente para encontrar suas próprias escolhas. (GROPIUS, 1965:26). O grande anseio do diretor Gropius, sob a ótica de Giulio Carlo Argan, era o de combater um cenário inevitável:

(...) "o indivíduo não capta a profunda razão construtiva dos objetos artísticos que condicionam sua existência a um espaço e a um tempo regulado sem os contatos com eles." E ainda complementa sobre, "Em virtude dessa experiência estética inerente ao fazer, nenhum trabalho será apenas executivo, mas implicando o momento da consciência ganhara valor criativo. (GROPIUS apud ARGAN, 1951:22).

A construção lógica do subsistema idealizador da escola tem como ponto de partida, segundo Fabrizio Caristi, o "hábito de pensar, idealizar e projetar o processo produtivo por inteiro" (CARISTI in DE MASI, 2007:231). A partir disso pode-se incentivar um importante senso crítico no estudante/aprendiz o qual é reforçado pelas palavras de Sennett quando diz que este: "focaliza a relação íntima entre a mão e a cabeça" (SENNETT, 2008:20). Este modelo estimula uma condicionante tanto na detecção quanto na solução de problemas projetuais de forma a proporcionar uma intervenção mínima na produção. Esta realidade, como retorna Caristi, "recupera simultaneamente o conhecimento do artesão e da capacidade criativa do artista" (CARISTI in DE MASI 2007:231). A escola adotava a obrigatoriedade do aluno cursar, após o ciclo básico, um período nas oficinas de modo a consolidar a relação entre projetar e executar efetivamente nos processos e artefatos gerados.

Contudo, foi observado que para exercer tal postura, o designer deveria estar em profunda imersão na realidade da produção. Não bastava apenas obter a informação como conhecimento teórico, mas sim vivê-lo como experiência. E, ressaltamos aqui, que esta realidade pode significar muito também para o processo de criação do designer. No sentido de aprofundarmos a importância da experiência no aprendizado, citamos o professor e Pedagogo Jorge Larrosa Bondia quando diz:

(...) a experiência, a possibilidade de que algo nos aconteça ou nos toque, requer um gesto de interrupção, um gesto que é quase impossível nos tempos que correm: requer parar para pensar, parar para olhar, parar para escutar, pensar mais devagar, olhar mais devagar, e escutar mais devagar; parar para sentir, sentir mais devagar, demorar-se nos detalhes, suspender a opinião, suspender o juízo, suspender a vontade, suspender o automatismo da ação, cultivar a atenção e a delicadeza, abrir os olhos e os ouvidos, 
falar sobre o que nos acontece, aprender a lentidão, escutar aos outros, cultivar a arte do encontro, calar muito, ter paciência e dar-se tempo e espaço. (BONDIA, 2002: 24)

\section{Entre teoria e prática}

As ferramentas tecnológicas atuais nos oferecem inúmeras informações. De acordo com Sennett (2013), programas de computador como o programa de arquitetura CAD (computer-assisted design: desenho com ajuda do computador), por exemplo, que em sua utilização se colocam como uma ameaça ao aprendizado envolvido entre o pensar e fazer. No caso do CAD, ao estabelecer os pontos na tela, deixando que os algoritmos do programa finalizem o desenho ligando linhas e vértices pela programação do sistema, o usuário apenas se preocupa em inserir sua conceituação. As empresas de arquitetura utilizam de forma unânime pela sua exatidão e agilidade. De fato, impressiona como são geradas as imagens, de modo realista, em sombras e texturas que são quase ilimitadas. E o próprio autor questiona: "como uma ferramenta tão poderosa poderia ter um efeito maléfico?" (SENNETT,2008:51)

Em pesquisa sobre o ensino de arquitetura em uma faculdade dos EUA, ele notou que uma jovem aluna retrata que ao desenhar ou projetar uma área, o traçado é absorvido na mente. Desta forma, não há apenas informação fornecida pelo computador, inicia uma experiência que não pode ser substituída pela máquina. O que não se registra se perderá facilmente. Neste sentido, Sennett conclui que:

Os esboços arquitetônicos frequentemente constituem imagens de possibilidades; no processo de cristalização e depuração pela mão, o projetista procede exatamente como um músico ou cozinheiro, envolve-se profundamente, amadurece suas ideias a respeito. (SENNET,2008:51)

Por outro lado, refletimos a partir de Sennett, que talvez os softwares utilizados pelos designers de comunicação visual, destinados a desenho, imagem e diagramação, seriam capazes de reduzir esta ameaça, quando buscam simular uma realidade material no ato do desenho, de modo que a construção visual se dê com inúmeras semelhanças à realidade material do profissional, pois conseguem traçar linhas, simular pinceladas, com uso de Pen Tablets controlar até o efeito da pressão no traçado, como se o designer estivesse realmente desenhando ou diagramando seus elementos na mesa de trabalho.

Entretanto, na fase de finalização da arte final para a impressão, ao gravar o arquivo digital, normalmente na extensão em PDF, para ser impresso e finalizado na gráfica, é necessária certa vivência em setor da oficina gráfica para garantir tal execução com sucesso. A forma como os softwares adotados em pré-impressão são elaborados e utilizados não reproduz a mesma realidade técnica de quando são impressos por meios tradicionais da impressão. Para exemplificar, podemos citar que a escolha errada na carga de tinta de uma imagem, ou a possibilidade de não prever o resultado da mistura de uma cor ao ser impressa em um papel que já possui uma cor própria como nos papéis kraft ou Pólen, podem ser fatores que comprometem toda a produção final. O fascínio do que vemos na tela do computador não traduz a realidade da impressão. Assim, os softwares, apesar de serem essenciais e necessários, devem ser vistos apenas como ferramentas virtuais que precisam do complemento do mundo real para serem utilizados com propriedade.

Neste sentido, o coordenador do Laboratório de Ensaios de Materiais de Construção e Estudos de Solo LEMC da FAU/EBA/UFRJ, Prof. Marcos Silvoso sustenta ainda, no campo da arquitetura, que o aluno necessita estar em completo diálogo com o fazer prático, e que o projeto não se encerra no computador. Essa relação com os materiais e processos precisa ser pensada de forma contínua. Os estudantes necessitam da prática para pensarem em soluções do projeto. Ele acrescenta que, se por um lado o uso dos programas de arquitetura facilita a visualização e construção da idealização do projeto, por outro, pode distanciar o futuro arquiteto das reais condições projetuais. Cria-se um projeto artificial. Ele acrescenta, ainda, que "um software gráfico próprio na criação de modelos em 3D na 
manipulação de plantas de arquitetura está flutuando, eles não possuem carga, eles não carregam o peso do mundo real." 2

Walter Benjamin em seu texto Experiência e Pobreza nos revela que não se pode esperar muito quando há ausência de experiência, na verdade tudo é reduzido, principalmente nossa percepção das coisas ao nosso redor. Apenas nos resta um único olhar fraco e turvo. Assim como Benjamin nos descreve, pode ser "uma forma nova de miséria que surge com esse monstruoso desenvolvimento a técnica." (BENJAMIN, 1985:115-116).

Desta forma, entendemos que apenas a informação ou teoria sobre a técnica é pobre de experiência no sentido de experimentar, testar e permitir certa liberdade em traçar caminhos não imaginados. Esse tipo de possibilidade é essencial na inovação entre materiais e processos que sem esta postura não poderiam ser previstos anteriormente.

\section{Experiência nas oficinas de aprendizagem: tecnologia versus experiência}

O presente artigo é parte da pesquisa de mestrado em andamento, intitulada "Design Faber - o meio de produção como forma e visualidade", uma investigação teórico-prática que pretende explorar e analisar parte da produção gráfica a partir dos seus processos e materiais com o objetivo de refletir sobre o envolvimento do designer no domínio da práxis. A seguir, ao narrar alguns casos de ensinoaprendizagem, por meio da observação de grupos específicos de estudantes em situação, permitimos um vislumbre do modo como estes processos e materiais, quando experimentados como parte integrante da criação no design visual, podem apontar novos caminhos antes não imaginados (BACHELARD, 2013), como parte da etapa de idealização do projeto.

No curso de extensão "Tecnologia e Artes Gráficas: criando e produzindo um impresso em gráfica ofsete", realizado por Leandro Ferreira Gatinho, autor deste artigo, em parceria com Raquel Ferreira da Ponte, Professora do curso de Comunicação Visual Design da Escola de Belas Artes, UFRJ, pode ser considerado situação exemplar de como o imprevisto gerado pela ação presente do fazer, nesse caso na fase de acabamento gráfico, pode modificar com sucesso aquilo que fora idealizado na etapa inicial do projeto. O curso foi oferecido em duas turmas e aconteceu na divisão gráfica da Universidade Federal do Rio de Janeiro nos setores de pré-impressão, impressão e pósimpressão em 2018.

Nas duas turmas, a proposta apresentada aos alunos do curso era de que eles desenvolvessem lâminas no formato A6, frente e verso em duas cores. Cada aluno deveria perguntar e responder a seguinte frase: "O que te move?". A pergunta entraria na frente e a resposta no verso.

Em relação ao acabamento das lâminas, propomos que estariam envolvidas por elásticos a fim de agrupá-las, tendo dois meio furos que manteriam o elástico na mediatriz da altura da lâmina (figura 2). Esses furos seriam feitos por uma máquina furadeira industrial e esse foi o planejamento prévio, elaborado sem que fossem realizados testes.

Ao operar a furadeira industrial, no setor de acabamento gráfico, enquanto o trabalho final da turma do segundo semestre de 2018 era executado, acabou sendo realizado um furo no local errado e, na tentativa de corrigir um erro de encadernação da furação, para não desperdiçar as lâminas impressas, o engano precisou ser compensar com mais furos, percebendo que novas possibilidades de utilização da ferramenta antes não pensadas, poderiam tornar o trabalho mais instigante (figuras 3 e 4 ). O resultado dos elásticos transpassados ficou semelhante as linhas do desenho já impresso de modo que o processo de encadernação reforçou a intenção do conteúdo semântico do trabalho.

Tal experiencia apresentada está em ressonância a atitude projetual que é valorizada durante a ação. Este pensamento é muito bem descrito em umas das falas do professor Ripper:

(...) "o nosso diferencial está no método, o nosso método é sempre não trilhado". E ele ainda adiciona que: (...) "Acreditamos não ser producente prever o caminho, senão não é novo, pelo menos para o Designer em atitude projetual. O que importa é trilhar um caminho próprio.” (RIPPER,2011:4)

\footnotetext{
2 SILVOSO, Marcos. Em “entrevista” gentilmente concedida à Leandro Ferreira Gatinho, na Faculdade de Arquitetura da Universidade Federal do Rio de Janeiro, no dia 08 de julho de 2019.
} 


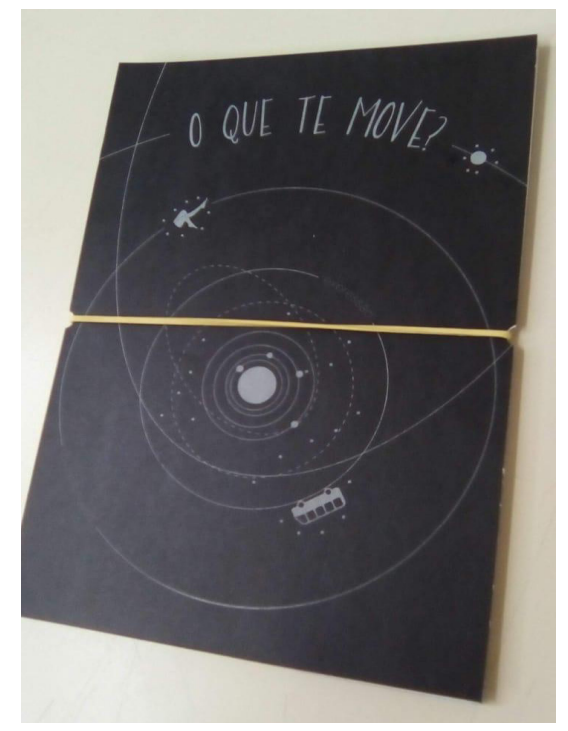

Figura 2 - Versão inicial do impresso, com o acabamento planejado Fonte: próprio autor

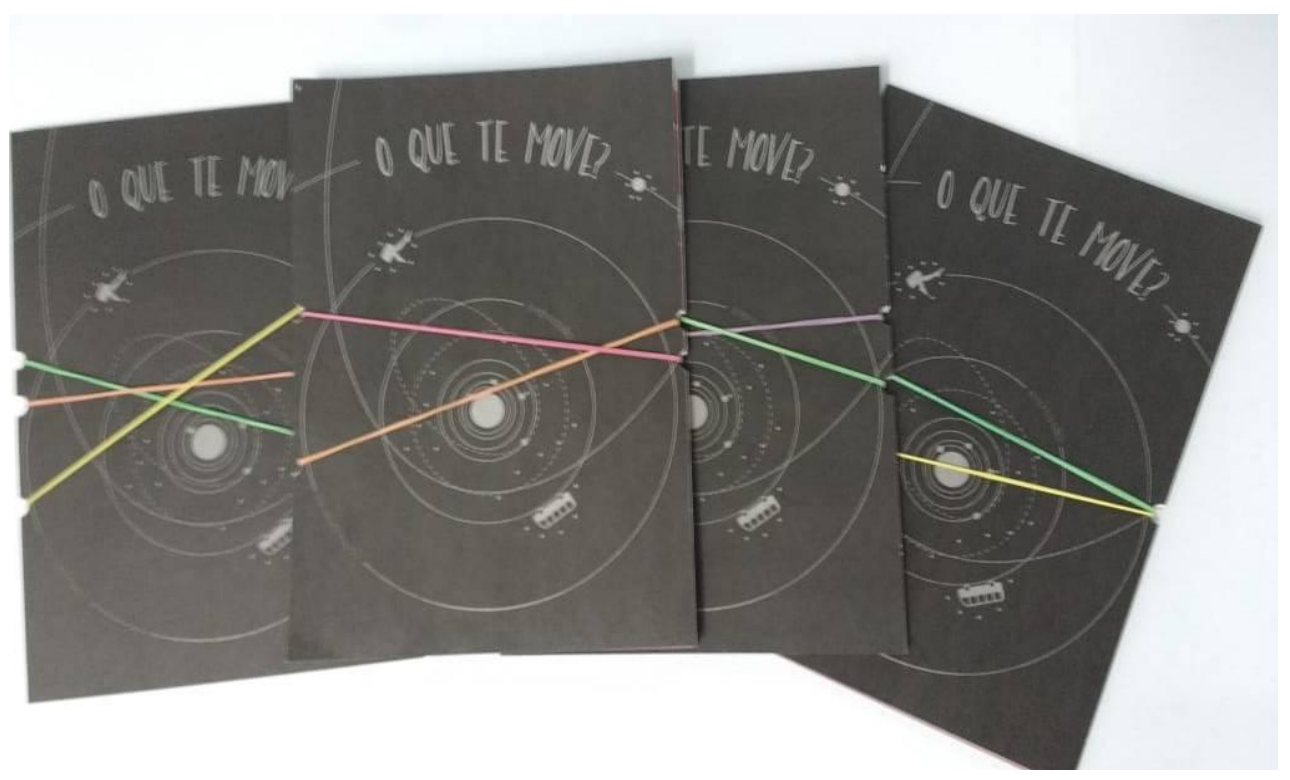

Figura 3 - Versão final, com a incorporação do erro+nova solução no processo de acabamento Fonte: próprio autor

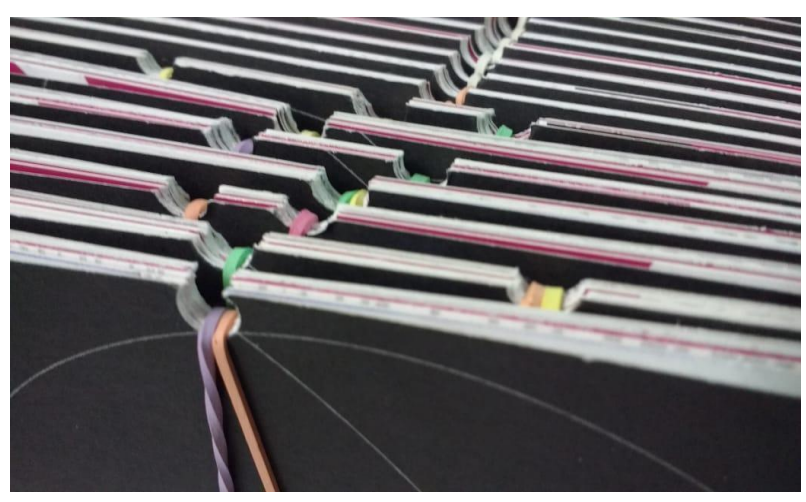

Figura 4 - Detalhe lateral da encadernação por meios furos com fixação por elásticos. Fonte: Própria do autor. 


\section{Experiência discente em outros processos gráficos}

O processo de impressão da gravura, por sua característica artesanal, já nos fornece um tipo de experiência do fazer humano que privilegia o tempo presente através do contato da matéria e da tinta de impressão. Na gravura de metal, por exemplo, a essência da imagem é transferida; a tinta é uma alma levada entre suportes, nasce no desenho das mãos, segue para a chapa e depois para o papel. É um tempo lento, quase suspenso, vivo; esse momento do fazer é sempre regido pelo tempo do agora. $\mathrm{E}$, como resultado, não se espera perfeição suprema ou exata, mas sim uma realidade humanizada, o acontecer entre erros e acertos, uma consequência do fazer humano.

Nessa técnica de impressão, que historicamente antecede os processos industriais, como a tipografia e o ofsete, pude acompanhar, como parte do meu estágio docência durante o mestrado em 2019, a experiência dos estudantes de graduação dos cursos de Comunicação Visual Design e Gravura, em uma turma formada por alunos desses dois cursos da Universidade Federal do Rio de Janeiro. A disciplina, nomeada Publicações independentes: do projeto à edição, foi ministrada pelo Professor de Gravura Pedro Sánchez e a Professora de Comunicação Visual Julie Pires. A proposta da disciplina visava oferecer aos alunos práticas projetuais que englobassem todas as etapas do projeto editorial, desde o planejamento até sua execução, com enfoque na realização de publicações individuais e coletivas, com o intuito de poder materializar edições de modo independente e autoral. Em sua pauta, foram apresentados diferentes exemplos de suportes, formatos e procedimentos de impressão na reprodução de imagens e textos, além de diversos processos de montagem, acabamento e encadernação. $\mathrm{O}$ curso aconteceu durante quatro semestres letivos, por meio de aulas teóricas e práticas oferecidas na oficina de gravura, da Universidade Federal do Rio de Janeiro. A partir desta iniciativa pedagógica, elaboradas pelos professores, os alunos deveriam conceber suas edições do briefing à finalização dos exemplares.

Diante desta experiência, percebi que para alguns estudantes o processo compreendeu mais do que uma possibilidade criativa, eles conseguiram obter um diálogo interessante entre a matéria (objeto), a técnica e o conteúdo. Deixaram que o projeto fosse se desenvolvendo, de modo que o ato de fazer pudesse estabelecer novas ações e sugerir novas soluções, sem que procurassem idealizar uma solução limitada previamente.

Entre os exercícios dessa disciplina, era almejado um entrelaçamento entre imaginar e fazer estabelecido desde o primeiro do trabalho. Citamos aqui o objetivo do primeiro projeto: de realização coletiva, no qual a proposta apresentada ao grupo pelos professores visava a elaboração individual de uma página quadrada com as dimensões $29 \times 29 \mathrm{~cm}$ (que poderia ser realizada em qualquer suporte flexível), na qual cada estudante deveria criar uma lógica para reprodução em 22 vezes (número de alunos por grupo) de uma "ação original" . Os meios para reprodução eram de total escolha do estudante, estabelecendo certa liberdade nas ações e gestos criadores, de acordo com a perspectiva de cada um. Muitas soluções distintas surgiram nessa proposta, desde a reprodução técnica com a utilização de saída por arquivo digital e fotocópia, até resultados inesperados como do estudante que a partir dos 22 suportes unidos (fixados por grampos e posicionados na vertical) despejou sobre o topo deles uma quantidade de tinta, de modo que a tinta ao avançar as 22 folhas de papel criassem figuras diferentes para cada uma dessas páginas. Houve, ainda, a título de exemplo, uma estudante que realizou seu trabalho na prensa do ateliê, no qual, o relevo gerado pela ação da prensa entre o papel e diversas moedas utilizadas como matriz, pode gerar formas com certa tridimensionalidade, e consequentemente informação visual e tátil.

Ao final do prazo estabelecido para os experimentos individuais, as 22 páginas realizadas por cada estudante foram unidas por meio de encadernação, com capa de criação coletiva e acabamento elaborado por toda a turma (em média formada por 40 alunos), resultando no produção final duas publicações (separadas em volume 1 e volume 2) contendo cada uma 22 páginas, as quais foram elaboradas por cada estudante da turma.

Ainda, a partir das observações de outra disciplina nesse mesmo atelier, descrevo a técnica da gravura em metal do trabalho da estudante Dora Romantini. Matriculada no sétimo período do curso

\footnotetext{
${ }^{3}$ A proposta teve elaboração inicial do Professor Pedro Sánchez, atualizada para cada turma da disciplina, e foi oferecida nos semestres de 2017.1 a 2018.2.
} 
de Gravura da Escola de Belas Artes, da Universidade Federal do Rio de Janeiro. ela relata que o que o mais lhe motiva, sempre, é tentar buscar caminhos diferentes do fazer convencional "linear". Buscar durante o processo da produção, algum retorno de visualidade, sem controle prévio. Assim, ela nos descreve o trabalho denominado "Luminescência Paradisíaca", o qual é constituído por quatro ensaios diferentes em placas de $15 \times 15 \mathrm{~cm}$, em escalas de cinza e cores. O processo iniciou com o polimento da placa de metal e depois a aplicação do breu para criar retículas. Em seguida, foi aplicado o ácido por várias camadas com o cuidado para que elas não se fechassem, pois caso isso ocorresse, a estudante precisaria voltar a lixar e recomeçar o processo. Dora conta que via seu trabalho como um verdadeiro exercício de arqueologia, entre revelar e escurecer a imagem. Já na imagem colorida (figura 5), um dos caminhos foi colocar várias camadas pertencentes as cores juntas para se misturarem após a limpeza. Por fim, ela narra que percebeu que algumas imagens criadas durante o processo de produção desta técnica, pareciam seguir uma espécie de "caminho orgânicos", no qual se desenhavam pelo próprio processo em seu desenvolvimento.

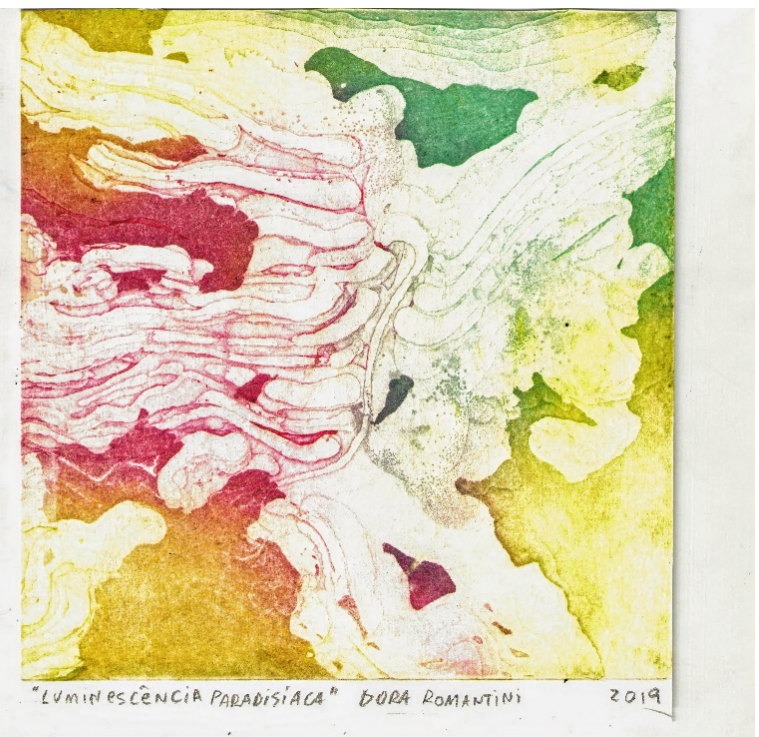

Figura 5: Impressão da gravura na versão em cores.

Fonte: Dora Romantini

Outro caso que vale citar, como um aprendizado reflexivo orientado pela experiência (BONDIA, 2002) a partir do envolvimento e uma situação proporcionada pela prática e o conhecimento vivido no cotidiano dos meios técnicos e processo gráficos, constitui o Trabalho de Conclusão de Curso, em Comunicação Visual Design, realizado pela estudante Juliana Misumi. O projeto apresentado em 2019, intitulado "amar.ela: sobre publicação independente, experiência manual e relações de afeto", orientado pelos professores e Julie Pires Pedro Sánchez, nos permite entender de que modo a vivência do estudante em suas práticas materiais pode gerar soluções inesperadas.

Durante o percurso desse TCC, atuei como estagiária na Editora Record, onde tive a chance de coletar uma das placas de polímero usadas na impressão dos livros. A Record conta com a máquina Cameron, um sistema de impressão único, que imprime as páginas usando placas de polímeros queimadas a partir dos fotolitos. O resultado é similar ao de uma gravura em borracha, ainda que o processo seja bastante diferente. Paralelo às gravuras feitas à mão, pude montar pequenos carimbos com o texto que entra no zine, a partir dessas placas. (MISUMI, 2019: 43)

Ex-aluna da disciplina "Publicações independentes: do projeto à edição", entre outras disciplinas realizadas no ateliê de gravura, e estagiária do Grupo Editorial Record, no Rio de Janeiro, a estudante Juliana Misumi uniu a gravura, do modo como já realizava antes em material flexível a partir dos princípios da xilogravura, ao uso de matrizes de impressão flexográfica, para criar 
"carimbos", matrizes em relevo, com o objetivo de imprimir algumas áreas da parte prática de seu trabalho de conclusão da Graduação (figura 6). Ela explica que por sua presença cotidiana na Editora, teve acesso às matrizes utilizadas no processo para a impressão de grandes tiragens ${ }^{4} \mathrm{e}$ com isso veio a chance de coletar algumas placas de polímero descartadas durante o processo da impressão de livros pelo Sistema Cameron, sistema baseado em impressão por matriz relevográfica, princípio gráfico também da xilogravura.
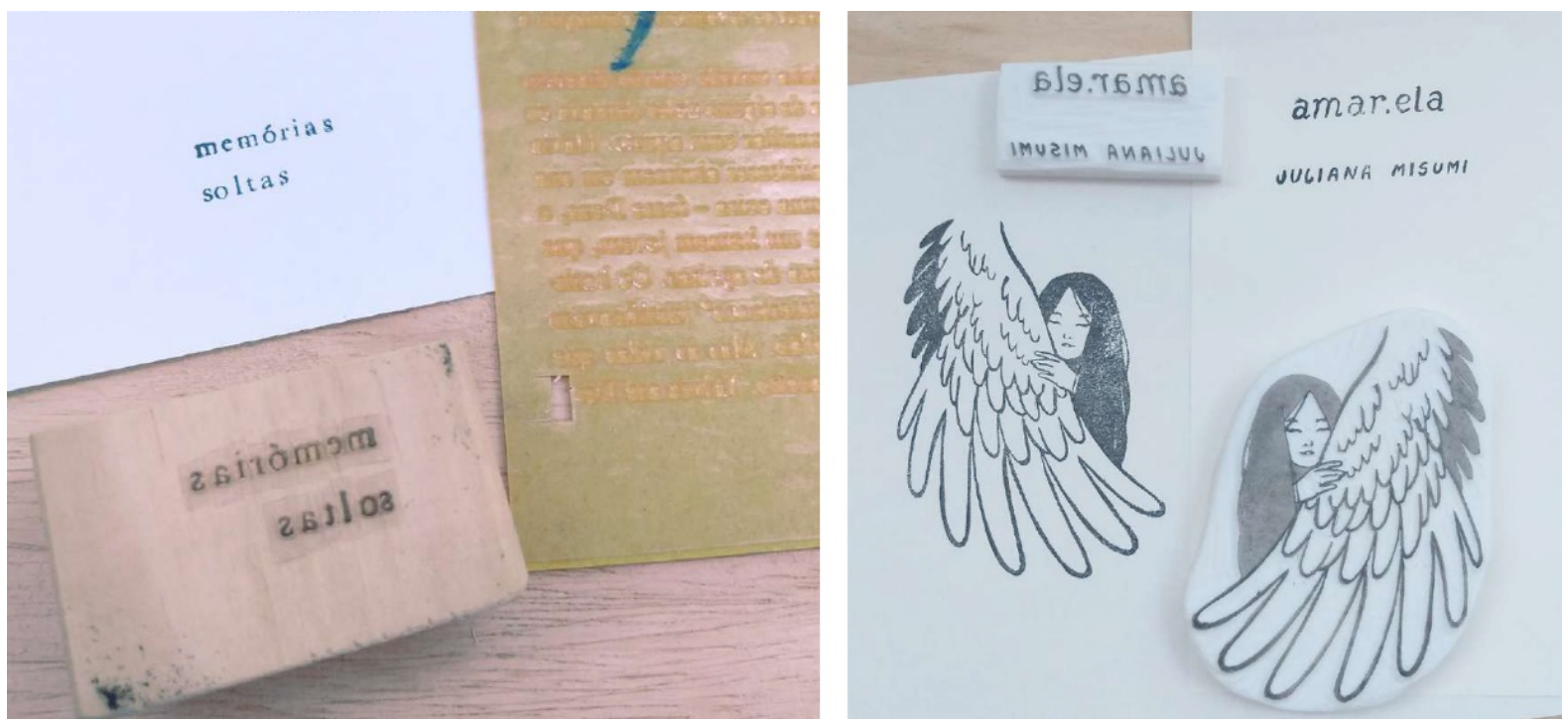

Figura 6: Matrizes de impressão do Trabalho de Conclusão de Curso.

Fonte: Juliana Misumi, monografia.

\section{Conclusão}

A intenção desta pesquisa é proporcionar outros olhares para a produção gráfica pelas lentes de um designer. Entendemos que este meio de materialização do objeto gráfico pode ser mais do que uma etapa executiva, em mera sequência linear. Por intermédio de exercícios gráficos realizados em oficinas de impressão e pós-impressão, somos estimulados a percorrer caminhos que não foram trafegados inicialmente, a fim de redirecionar a linearidade das resultantes de um processo fabril, cujas formas e ações básicas, como o ponto, a linha, a criação de planos e, até mesmo na manipulação dos suportes, como a maneira de dobrar o papel, não foram pensadas no início do projeto. Essas atitudes podem ser estimuladas no estudante de design, desde o início de seu aprendizado, mas também ao longo da formação, para fomentar o intuito de extrair de seus materiais, através da manipulação da matéria, possibilidades de novas formas geradoras e do surgimento inusitado de suas visualidades.

Contudo, estima-se que esta rota apenas será desvendada se a postura do designer vier embutida do poder transformador, de uma alquimia do fazer. E, para ter a consciência dessa potência do fazer, o designer precisa unir em suas práticas ação e pensamento, em todas as etapas do processo, para uma materialização impar do seu projeto gráfico. Não pode ser apenas uma criação conceitual ou teórica sem a formalização do possível, do que se pretende conceber. Acreditamos que somente a partir do conhecimento como experiência, a produção gráfica poderá ser concretizada, tornando o possível real.

\footnotetext{
${ }^{4}$ O Sistema Poligráfico Cameron, utilizado pelo grupo editorial Record, é único na América Latina e compreende máquinas de impressão e acabamento, capazes de reproduzir 100 livros de 200 páginas por minuto. (Fonte: www.record.com.br)
} 
The means of production as form and graphic language: the making experience as a power in the design teaching-learning process

Abstract: This paper belongs to a design master's research that aims to reflect on the creative process and a graphic design interactive teaching-learning approach based on experience with materials and techniques from the offset industry. We think that we can find new design solutions when acquired knowledge by the project approach focused on the experience from the process and the graphic industry material as a learning e creative process. When the graphic printing production process assumes other perspectives rather than finish points on linear steps projects, they are not only mere mechanical productive acts. Further, this projective attitude can be stimulated in design students in order to extract from its materials, through the manipulation of matter, new possible forms. For these results, he needs to master the process, through experience, reaching not only the materialization of his graphic project but making the real possibility, by potentiating their creative process from a technique, as a designer and an artist's point of view. Even generating poetic possibilities. The writings of Richard Sennett, Gaston Bachelard, Rafael Cardoso, Jorge Larrosa, among others, contributed to this reflection.

Keywords:

graphic printing production; craftsmanship; visual communication design; teaching-learning

\section{Referências bibliográficas}

ARGAN, Giulio Carlo. "Walter Gropius e a Bauhaus" Lisboa: Editorial José Olympio, 2005.

BACHELARD, Gaston. A terra e os devaneios da vontade. Ensaio sobre a imaginação das forças. São Paulo: Martins Fontes, 2013.

BARBOSA, Regina. A Obra de Arte Total: Ideias interdisciplinares da secessão Vienense. In $\boldsymbol{8}^{\mathbf{0}}$ Congresso de Pesquisa e Desenvolvimento, 2008. apud STOLASKI, André. Design e Arte: campo minado - uma antologia de discursos comentados e uma proposta disciplinar. Dissertação (Mestrado - área de concentração: projeto espaço e cultura) - FAUUSP, São Paulo, 2012.

BENJAMIN, Walter. A Obra de Arte no Tempo de Sua Reprodutibilidade Técnica in "Os Pensadores" Editora Abril, 1975, São Paulo.

BENJAMIN, Walter. Magia e Técnica, Arte e Política. São Paulo: Ed. Brasiliense, 1985.

BOMFIM, Gustavo Amarante. Fundamentos de uma Teoria Transdisciplinar do Design: morfologia dos objetos de uso e sistemas de comunicação. In: Estudos em Design, Volume 5, n 2, dez 1997. p. 2741.

BONDIA, Jorge Larrosa. Notas sobre a experiência e o saber de experiência. Revista Brasileira de Educação, n. 19, jan./abr. 2002.

CARDOSO, Rafael. Design para um mundo complexo. São Paulo: Cosac Naify, 2012.

CARDOSO, Rafael. Uma introdução à história do design. São Paulo: Blucher, 2008.

CARISTI, Fabrizio. Uma ponte entre artesanato, arte, indústria e academia. In. A emoção e a regra: os grupos criativos na Europa de 1850 a 1950. Organizado por Di MASI, Domenico. 9a ed. Rio de Janeiro: José Olympio, 2007. 230 - 232 p.

FARBIARZ, Jackeline e Ripper, José Luiz. Design em Parceria: visitando a metodologia sob a perspectiva do Laboratório de investigação em Living Design da PUC-Rio. In: Luiz Antônio L. Coelho; Denise Westin. (Org.). Estudo e Prática em Metodologia em Design nos cursos de pós-graduação. Teresópolis: Novas Ideias, 2011. p.186-213. 
GROPIUS, Walter. Bauhaus: Novarquitetura. São Paulo: Editora Perspectiva, Coleção Debates no 47, $2^{\mathrm{a}}$ edição, 1974.

MISUMI, Juliana. Amar.ela: sobre publicação independente, experiência manual e relações de afeto. 2019. 53 f. Orientação: Julie A. Pires e Pedro Sánchez. Trabalho de Conclusão de Curso (Graduação em Comunicação Visual - Design) - Escola de Belas Artes, Universidade Federal do Rio de Janeiro, Rio de Janeiro, 2019.

SENNET, Richard. O Artífice. Rio de janeiro: Record, 2009.

STOLARSKI, Andre. Design e arte: campo minado uma antologia de discursos comentados e uma proposta disciplinar. 2012. Tese de Douorado. Universidade de São Paulo. 